\title{
Charge States of y lons in the Collision-Induced Dissociation of Doubly Charged Tryptic Peptide Ions
}

\author{
Pedatsur Neta, Stephen E. Stein
}

Chemical and Biochemical Reference Data Division, National Institute of Standards and Technology, Gaithersburg, Maryland, USA

\begin{abstract}
Bonds that break in collision-induced dissociation (CID) are often weakened by a nearby proton, which can, in principle, be carried away by either of the product fragments. Since peptide backbone dissociation is commonly charge-directed, relative intensities of charge states of product $y$ - and b-ions depend on the final location of that proton. This study examines $y$-ion charge distributions for dissociation of doubly charged peptide ions, using a large reference library of peptide ion fragmentation generated from ion-trap CID of peptide ions from tryptic digests. Trends in relative intensities of $\mathrm{y}^{2+}$ and $\mathrm{y}^{1+}$ ions are examined as a function of bond cleavage position, peptide length $(n)$, residues on either side of the bond and effects of residues remote from the bond. It is found that $y_{n-2} / b_{2}$ dissociation is the most sensitive to adjacent amino acids, that $\mathrm{y}^{2+} / \mathrm{y}^{1+}$ steadily increase with increasing peptide length, that the $\mathrm{N}$-terminal amino acid can have a major influence in all dissociations, and in some cases other residues remote from the bond cleavage exert significant effects. Good correlation is found between the values of $\mathrm{y}^{2+} / \mathrm{y}^{1+}$ for the peptide and the proton affinities of the amino acids present at the dissociating peptide bond. A few deviations from this correlation are rationalized by specific effects of the amino acid residues. These correlations can be used to estimate trends in $\mathrm{y}^{2+} / \mathrm{y}^{1+}$ ratios for peptide ions from amino acid proton affinities.
\end{abstract}

Key words: Peptide, Proteomics, Fragmentation, Electrospray

\section{Introduction}

$\mathrm{P}$ eptide ion fragmentation by tandem mass spectrometry has become a routine means of determining peptide sequence for the purpose of protein identification [1]. This is commonly done by assigning product ion $\mathrm{m} / \mathrm{z}$ values to yand $\mathrm{b}$ - ions originating from the $\mathrm{C}$ - or $\mathrm{N}$-terminal fragments of the original peptide ion. However, in the common case of charge directed fragmentation, each of these ions may exist

Electronic supplementary material The online version of this article (doi:10.1007/s13361-011-0089-9) contains supplementary material, which is available to authorized users.

Correspondence to: Stephen E. Stein; e-mail: steve.stein@nist.gov in two different charge states (or one may be a neutral product), depending on the location of the charge that activates the bond breaking. Loss of neutral amino acids or peptide fragments from multiply charged peptide ions has been observed and discussed before [2-5]. In this work we examine factors that determine the relative fraction of the protons that attach to the $\mathrm{y}$ - or b-fragment by using a library of more than 285,000 unique MS/MS spectra of doubly charged peptide ions.

Peptide fragmentation trends derived from large collections of spectra have been published by several groups, for example [6-11], and recently reviewed [12]. Most of these studies examined the effect of specific residues, especially those adjacent to the breaking bond, and their relation to "proton mobility", on the extent of formation of specific 
fragments, mainly $\mathrm{y}$ and $\mathrm{b}$ ions. This has led to the creation of rules and trends now widely used in the analysis of peptide fragmentation. Given the diversity of lengths, sequences, mobile protons and charges, the size of these collections was insufficient to examine certain effects, for example many of those depending on peptide length. In the course of developing a spectral library, we have developed a collection an order of magnitude larger than those previously available, and have undertaken to examine effects requiring larger collections [9]. In the present study, we make use of this increased size to examine factors that determine relative rates of formation of singly- and doubly-charged fragment ions. In fact, charge state ratios were cited as an example of a fragmentation property in need of further study [9].

Irrespective of the site of fragmentation, it is often assumed that doubly charged peptide ions form two singly protonated ions, generally $b_{x}$ and $y_{n-x}$. However, a quick scan of our libraries of MS/MS spectra of peptide ions, which contain spectra for over half a million peptide ions, indicates that, in many cases, the y ions are observed in two charge states, i.e. both singly protonated and doubly protonated, in some cases the doubly charged state being the larger peak. In the present study we examine the relationship between the likelihood of formation of doubly protonated y ions and the amino acid residues surrounding the peptide bond being cleaved. We examine the relative intensities of the doubly charged to singly charged y ions, I $\left(\mathrm{y}^{2+}\right) / \mathrm{I}\left(\mathrm{y}^{1+}\right)$, focusing first on $\mathrm{y}_{\mathrm{n}-2}$, because of its prevalence, and then also examining $\mathrm{y}_{\mathrm{n}-1}$ and $\mathrm{y}_{\mathrm{n}-3}$ formation.

\section{Results}

MS/MS spectra contained in six libraries of peptide mass spectra: human, yeast, E. Coli, mouse, drosophila, and C. Elegans were examined [http://peptide.nist.gov]. These studies examined the 285,539 unique MS/MS spectra in these libraries of doubly charged tryptic peptide ions composed of $\leq 16$ residues, all with $\mathrm{K}$ or $\mathrm{R}$ at the $\mathrm{C}$ terminus. All spectra were acquired on ion-trap instruments and derived from multiple spectra [13, 14], thereby minimizing noise peaks. The relative intensity of the singly and doubly charged ions can strongly depend on the specific residues adjacent to the breaking bond, and in some cases the doubly charged form predominates. Intensities of each yion in a spectrum were derived as fractions of total y-ion intensity for the spectrum and all $\mathrm{y}^{+1}$ and $\mathrm{y}^{+2}$ ions were used, whether they co-occurred in a spectrum or not. Medians of these values were used in all calculations. The statistical analysis of the MS/MS data was carried out using software that was developed in house.

\section{Effect of Vicinal Amino Acid Residues}

First, we examined the ratio of charge states for the peptide bond cleavage forming $\mathrm{y}_{\mathrm{n}-2}$ ions from doubly charged peptide ions. We collected these ratios for all the peptides in which a specific amino acid residue is located at a specific position in the peptide sequence. The median ratio of the peak intensities $\mathrm{I}\left(\mathrm{y}_{\mathrm{n}-2}{ }^{2+}\right) / \mathrm{I}\left(\mathrm{y}_{\mathrm{n}-2}{ }^{1+}\right)$ is plotted as a function of peptide length for all peptides with specific amino acids at positions 1, 2, 3, and 4 (Figure 1). Most curves show a gradual increase in this ratio (by two or three orders of magnitude) with increasing peptide length, which is presumably related to the fact that longer y ions can more readily accommodate two protons than the shorter ones. Figure $1 \mathrm{c}$ and $\mathrm{d}$ are for residues at positions 3 and 4, i.e. these amino acids remain in the $\mathrm{y}_{\mathrm{n}-2}$ ion formed. In these cases, the basic amino acids $\mathrm{H}$ and $\mathrm{K}$, represented by the top curves, give the highest ratios of $\mathrm{I}\left(\mathrm{y}_{\mathrm{n}-2}{ }^{2+}\right) / \mathrm{I}\left(\mathrm{y}_{\mathrm{n}-2}{ }^{1+}\right)$, whereas $\mathrm{G}$, the least basic residue, gives the lowest ratios. Comparison of Figure $1 \mathrm{c}$ and $\mathrm{d}$ shows that the curves for residues at position 4 are closer together than those for residues at position 3, i.e. in most cases the effects of amino acids diminish with their distance from the cleaving peptide bond. Since most curves in these two plots are essentially parallel, their relative vertical positions should be representative of the relative proton affinities of the amino acid residues. Spectra underlying these and other values reported here show a large dispersion of $\mathrm{I}\left(\mathrm{y}_{\mathrm{n}-2}{ }^{2+}\right) / \mathrm{I}\left(\mathrm{y}_{\mathrm{n}-2}{ }^{1+}\right)$ values, typically showing a median absolute deviation of a factor of two to three (see Supplementary Table 1), due to the multiple sources of variation described later. However, the steady changes in median values with increase in peptide length, and the generally parallel trends of different residues, show that these median values are stable and reproducible since each value is based on an entirely different set of spectra.

Figure 1a and $\mathrm{b}$, for residues at positions 1 and 2, also show somewhat parallel curves but with a number of deviations. The most pronounced deviation is for $\mathrm{R}$, where the dependence on peptide length is minimal. In other words, arginine in position 1 or 2 binds the proton tightly at its guanidine moiety and thus permits only minimal amounts of $\left(\mathrm{y}_{\mathrm{n}-2}\right)^{2+}$ ions, almost irrespective of peptide length. Another deviation from the standard curvature is seen for $\mathrm{P}$ at position 2, probably related to the fact that peptide bonds at the $\mathrm{C}$-terminus of $\mathrm{P}$ are notoriously difficult to cleave. The deviation of $\mathrm{N}$-terminal $\mathrm{E}$ and $\mathrm{Q}$ from the general trends in Figure 1a is related to the rapid loss of water from these amino acids when located at the N-terminus, and the apparent lowering of the proton affinity of the N-terminus after this reaction [15]. The effect of $G$ for disfavoring charge retention is unique, being especially large in both the 1 and 2 positions, but only for smaller peptides.

Comparison of the two top plots with the two bottom plots in Figure 1 shows that the approximate order of amino acid curves changes direction. When the basic residues are included in the y ions being formed, this y ion is more likely to be at the higher charge state. On the other hand, when the basic residues are in the $\mathrm{b}$ fragment, the $\mathrm{y}$ ion is more likely to be singly charged. This agrees with general trends reported before $[2,4]$. 


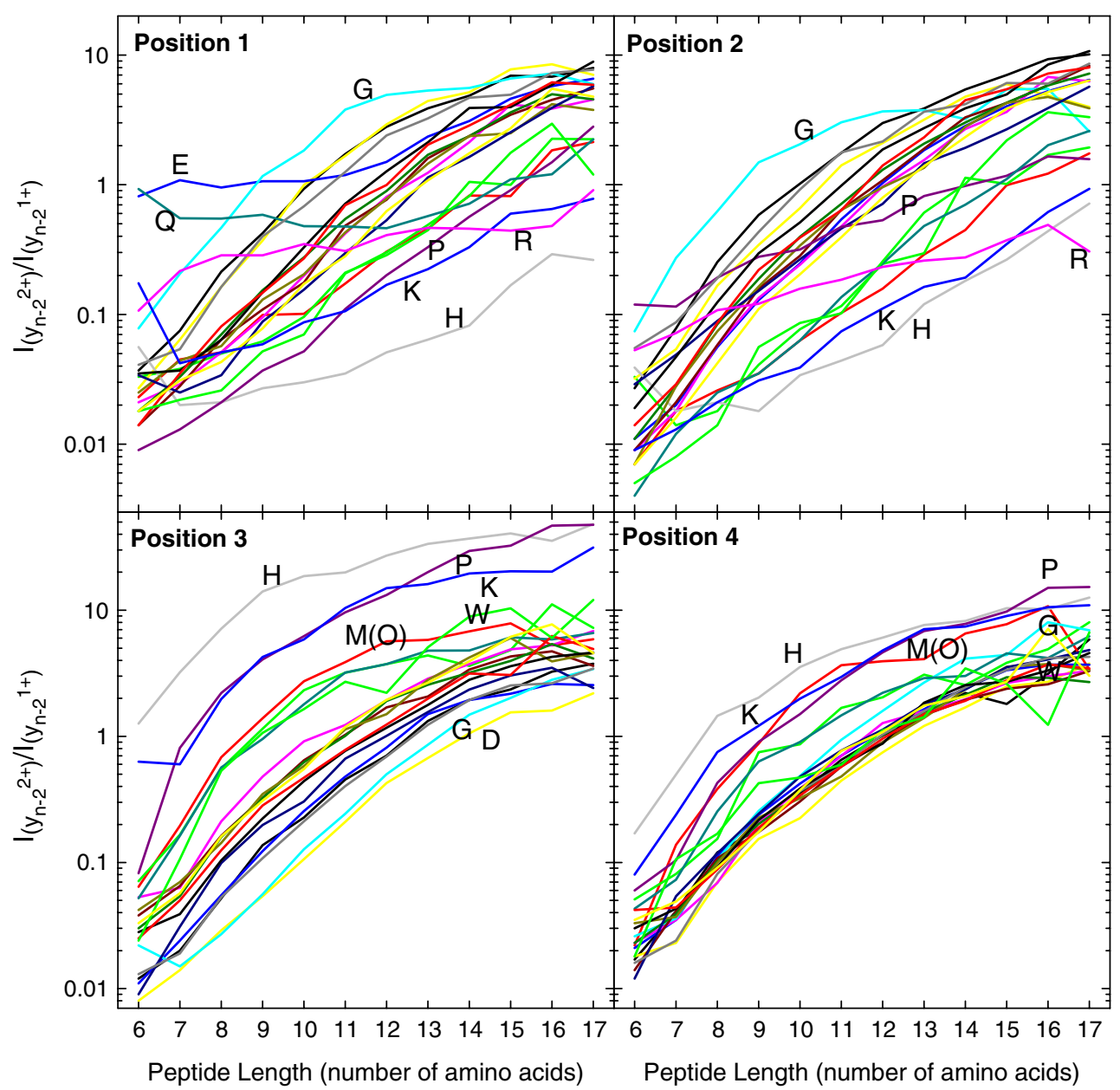

Figure 1. Relative intensities of $\mathrm{y}_{\mathrm{n}-2^{2+}} \mathrm{vs}^{2+} \mathrm{y}_{\mathrm{n}-2}{ }^{1+}$ peaks in CID of doubly charged tryptic peptide ions containing 6 to 17 amino acid residues with specific residues at position 1, 2, 3, or 4 in the peptide chain ( 1 being the $\mathrm{N}$-terminus). Each curve is for a specific residue. Only the extreme curves are marked with the residue symbol

The relative vertical positions of the curves are expected to be related to the proton affinity of the specific residue represented by that curve. To compare the effects of amino acids at opposite ends of the cleaving peptide bond, we took the values for residues at positions 2 and 3 from Figure $1 b$ and $\mathrm{c}$, averaged the $\mathrm{I}\left(\mathrm{y}_{\mathrm{n}-2}{ }^{2+}\right) / \mathrm{I}\left(\mathrm{y}_{\mathrm{n}-2}{ }^{1+}\right)$ values in the middle parts of the curves (for peptides with 10 to 13 residues) and plotted the values together in Supplementary Figure S1, showing that the amino acids at positions 2 and 3 exert opposite effects. Figure 2 shows plots of the same average values of $\mathrm{I}\left(\mathrm{y}_{\mathrm{n}-2}{ }^{2+}\right) / \mathrm{I}\left(\mathrm{y}_{\mathrm{n}-2}{ }^{1+}\right)$ vs. the proton affinities of the amino acid molecules. The values of the proton affinities were taken from Bleiholder et al. [16], who considered the values reported earlier by Harrison [17], Hunter and Lias [18], and others, and revised some of them. The value for oxidized methionine, $\mathrm{M}(\mathrm{O})$, was not included in those reports and was taken from Lioe et al. [19]. Figure 2 shows a clear correlation with the proton affinity and also demonstrates the opposing trends for residues at position 2 vs. 3. A strong deviation is observed for proline; when it is at position 3 it is known to enhance fragmentation to $b_{2}$ and $\mathrm{y}_{\mathrm{n}-2}$ and it also increases the ratio $\mathrm{I}\left(\mathrm{y}_{\mathrm{n}-2}{ }^{2+}\right) / \mathrm{I}\left(\mathrm{y}_{\mathrm{n}-2}{ }^{1+}\right)$ relative to the value expected from its effect when in position 2. In contrast with proline, aspartic and glutamic acids at position 3 decrease the ratio $\mathrm{I}\left(\mathrm{y}_{\mathrm{n}-2}{ }^{2+}\right) / \mathrm{I}\left(\mathrm{y}_{\mathrm{n}-2}{ }^{1+}\right)$ compared with that expected from their behavior when in position 2. These specific effects have been noted before [4]. Arginine is not included in this plot because of its different behavior, as discussed above. Regression analysis of the data for amino acids at position 2 gives a correlation coefficient $\mathrm{R}=0.93$. Comparison of the experimental points with the values calculated from the correlation equation shows deviations with a mean value of $21 \%$ (average value of $31 \%$ ). It also shows that median values of $\mathrm{I}\left(\mathrm{y}_{\mathrm{n}-2}{ }^{2+}\right) / \mathrm{I}\left(\mathrm{y}_{\mathrm{n}-2}{ }^{1+}\right)$ for all the amino acids can be predicted to better than \pm a factor of 2 , and that, except for $\mathrm{H}, \mathrm{W}$, and $\mathrm{M}(\mathrm{O})$, they can be predicted to better than $\pm 50 \%$. The deviations may be due to differences in the charge separation barriers and differences between the proton affinities of the amino acid molecules, which are used in the correlation, and the proton affinities of the amino acid residues within the peptide, which are unknown. The differences between these two types of proton affinities may vary for different residues. Therefore, the values of $\mathrm{I}\left(\mathrm{y}_{\mathrm{n}-2}{ }^{2+}\right) / \mathrm{I}\left(\mathrm{y}_{\mathrm{n}-2}{ }^{1+}\right)$ obtained for the different 


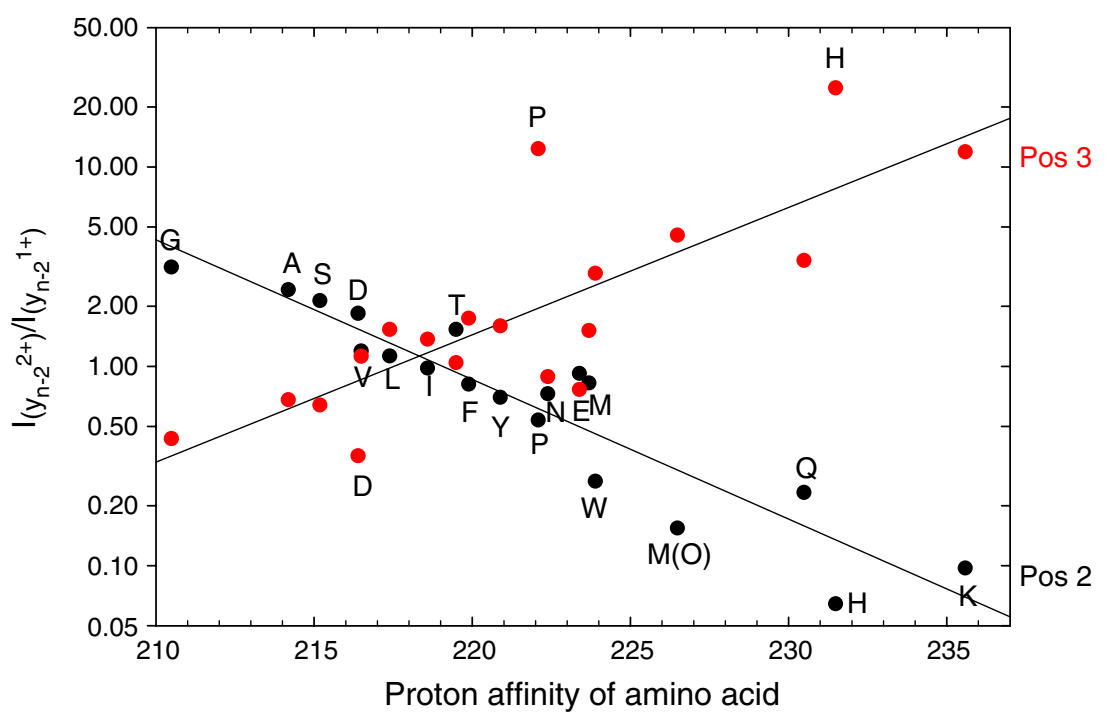

Figure 2. The average values of $\mathrm{I}\left(\mathrm{y}_{\mathrm{n}-2^{2+}}\right) / \mathrm{I}\left(\mathrm{y}_{\mathrm{n}-2}{ }^{1+}\right)$ for peptides with 10 to 13 amino acid residues (from Figure 1) with specific residues at position 2 or 3 vs. the proton affinities of the amino acids at these positions

residues may be better predictors of this ratio for other peptides than the values of proton affinities for the specific amino acid at the dissociating peptide bond. If the proton affinity of the residue is the predominant factor determining the value of $\mathrm{I}\left(\mathrm{y}_{\mathrm{n}-2}{ }^{2+}\right) / \mathrm{I}\left(\mathrm{y}_{\mathrm{n}-2}{ }^{1+}\right)$, then these values may be considered also as predictors of this proton affinity.

Somewhat similar results were found for peptide fragmentation to form $b_{1}$ and $y_{n-1}$ ions, although this fragmentation is less common than that between positions 2 and 3 discussed above. The values of $\mathrm{I}\left(\mathrm{y}_{\mathrm{n}-1}{ }^{2+}\right) / \mathrm{I}\left(\mathrm{y}_{\mathrm{n}-1}{ }^{1+}\right)$ vary with peptide length and depend on the adjacent amino acid residues (Supplementary Figure S2) in the same manner as discussed above. By averaging the values of $\mathrm{I}\left(\mathrm{y}_{\mathrm{n}-1}{ }^{2+}\right) / \mathrm{I}\left(\mathrm{y}_{\mathrm{n}-1}{ }^{1+}\right)$ for peptides with 9 to 12 residues, we find a dependence of the average values on proton affinity (not shown) similar to that in Figure 2, although with slightly more scattered data.

We also examined the data for peptide fragmentation to form $\mathrm{b}_{3}$ and $\mathrm{y}_{\mathrm{n}-3}$ ions using the same procedures. The dependence on peptide length and on amino acid (Figure 3) is similar to that discussed above for fragmentations at other sites. By averaging the values of $\mathrm{I}\left(\mathrm{y}_{\mathrm{n}-3}{ }^{2+}\right) / \mathrm{I}\left(\mathrm{y}_{\mathrm{n}-3}{ }^{1+}\right)$ for peptides with 10 to 13 residues, we find a dependence of the average values on proton affinity (Figure 4) similar to that found for $\mathrm{I}\left(\mathrm{y}_{\mathrm{n}-2}{ }^{2+}\right) / \mathrm{I}\left(\mathrm{y}_{\mathrm{n}-2}{ }^{1+}\right)$ (Figure 2), but with a five times smaller range in the vertical scale. This smaller range means that rates of breaking the 2-3 bonds are five times more sensitive to adjacent amino acid variations than are 3-4 bonds. Other data (not shown) indicate that bonds further away from the N-terminus are similar to the 3-4 bond, so that the 2-3 bond breaking is inherently more sensitive to charge location than interior bonds in the peptide.

\section{Effect of Remote Amino Acid Residues}

The above results for $\mathrm{y}_{\mathrm{n}-2}$ ions indicate that there is a strong dependence of the $\mathrm{I}\left(\mathrm{y}_{\mathrm{n}-2}{ }^{2+}\right) / \mathrm{I}\left(\mathrm{y}_{\mathrm{n}-2}{ }^{1+}\right)$ values on the amino acid residues directly involved in the bond being cleaved, i.e. those at positions 2 and 3, and that adjacent residues, at positions 1 and 4, may also exert some effect. To estimate the effect of residues remote from the cleaving bond (i.e. at positions $1,4,5$, etc.), it is necessary to compensate for the widely varying effects of the residues at positions 2 and 3 . For this purpose, we divided the peptides into groups defined by their length and their residues at positions 2 and 3. For each group we calculated the median value of $\mathrm{I}\left(\mathrm{y}_{\mathrm{n}-2}{ }^{2+}\right) / \mathrm{I}\left(\mathrm{y}_{\mathrm{n}-2}{ }^{1+}\right)$ for each amino acid at each remote position and related it to the I $\left(\mathrm{y}_{\mathrm{n}-2}{ }^{2+}\right) / \mathrm{I}\left(\mathrm{y}_{\mathrm{n}-2}{ }^{1+}\right)$ value for the pair at positions 2 and 3. In other words, we calculated $\left[\mathrm{I}\left(\mathrm{y}_{\mathrm{n}-2}{ }^{2+}\right) / \mathrm{I}\left(\mathrm{y}_{\mathrm{n}-2}{ }^{1+}\right)\right]_{\mathrm{x}} /\left[\mathrm{I}\left(\mathrm{y}_{\mathrm{n}-2}{ }^{2+}\right) / \mathrm{I}\left(\mathrm{y}_{\mathrm{n}-2}{ }^{1+}\right)\right]_{2,3}$. The results are shown in Figure 5 for peptides with 10 and 12 amino acid residues. In these plots, the values shown for positions adjacent to the breaking bond ( 2 and 3 ) are fixed at 1 , as they were taken as reference for residues at remote positions. It is clear in most cases that the effect of a residue at position 1 is reversed from its effect at position 4 , as discussed above. When the amino acid is further removed from the breaking bond, i.e. at position 5 and beyond, its effect is more moderate than at position 4, except for the basic amino acids, whose effects depend little on position. This effect is evident from more detailed results for histidine (Supplementary Figure S3) where high positive values for $\left[\mathrm{I}\left(\mathrm{y}_{\mathrm{n}-2}{ }^{2+}\right) / \mathrm{I}\left(\mathrm{y}_{\mathrm{n}-2}{ }^{1+}\right)\right]_{\mathrm{x}} /\left[\mathrm{I}\left(\mathrm{y}_{\mathrm{n}-2}{ }^{2+}\right) / \mathrm{I}\right.$ $\left.\left(\mathrm{y}_{\mathrm{n}-2}{ }^{1+}\right)\right]_{2,3}$ are found for all peptides with various lengths.

In contrast, the results for proline (Supplementary Figure S4) show a strong effect in vicinal positions but a much weaker effect at distant positions. These results include forming the $\mathrm{y}_{\mathrm{n}-1}, \mathrm{y}_{\mathrm{n}-2}$, and $\mathrm{y}_{\mathrm{n}-3}$ ions. The cleaving bond is assigned position 0 and given a value of 1 and the values for proline at positions $1,2,3$, etc. toward the C-terminus or positions -1 and -2 toward the $\mathrm{N}$-terminus are calculated for peptides with various lengths. The plots with large changes in the values on the vertical scale are for peptide ions forming $\mathrm{y}_{\mathrm{n}-1}$ and $\mathrm{y}_{\mathrm{n}-2}$ ions, and the plots 




Figure 3. Relative intensities of $\mathrm{y}_{\mathrm{n}-3^{2+}}$ vs. $\mathrm{y}_{\mathrm{n}-3^{1+}}$ peaks in CID of doubly charged tryptic peptide ions containing 7 to 14 amino acid residues with specific residues at position 3 or 4 in the peptide chain ( 1 being the $\mathrm{N}$-terminus). Each curve is for a specific residue. Only the extreme curves are marked with the residue symbol with smaller peaks are for peptides forming $\mathrm{y}_{\mathrm{n}-3}$ ions. This is in line with the above observations on the different effects on these various bond fragmentation processes. As noted above, the effect of aspartic acid is reversed and weaker from that of proline, and this is evident also in Figure S4.

One special remote effect is that of the C-terminal amino acid, which is generally $\mathrm{R}$ or $\mathrm{K}$ for tryptic peptides. In Table 1 we compare the results for $\mathrm{R} v s$. $\mathrm{K}$ for doubly charged peptide ions with 6 to 15 amino acid residues, dissociating the bonds between residues $1-2,2-3$, and $3-4$. Figure S5 shows a graphical representation of the relative intensities $\mathrm{y}^{2+} / \mathrm{y}^{1+}$ for the various $\mathrm{y}$ ions formed $\left(\mathrm{y}_{\mathrm{n}-1}, \mathrm{y}_{\mathrm{n}-2}\right.$, and $\left.y_{n-3}\right)$. The ratio between the values for $R$ and $K$ is about the same for the various y ions and various peptide lengths, except for the $\mathrm{y}_{\mathrm{n}-3}$ ions formed from the short peptides, where the ratio is reversed. This deviation becomes more pronounced for $\mathrm{y}_{\mathrm{n}-4}$ and $\mathrm{y}_{\mathrm{n}-5}$ ions (data not shown). The reason for this trend favoring $\mathrm{K}$ over $\mathrm{R} \mathrm{C}$-termini with proximity to the $\mathrm{C}$-terminus is unclear and will be the topic of future studies. The finding that charge retention on the y-ion is generally favored for R- vs. K-terminated peptides, even for rather long peptides, may arise from a higher 'shielding' of the proton in the guanidine moiety compared to a simple protonated amine.

\section{Discussion}

Collision induced dissociation of doubly charged tryptic peptide ions can produce either singly charged $\mathrm{y}$ and $\mathrm{b}$ ions or doubly charged y ions and a neutral fragment. Loss of neutral amino acids or peptide fragments from multiply charged peptide ions has been observed and discussed before [2-5]. The extent of loss of neutral amino acid or peptide

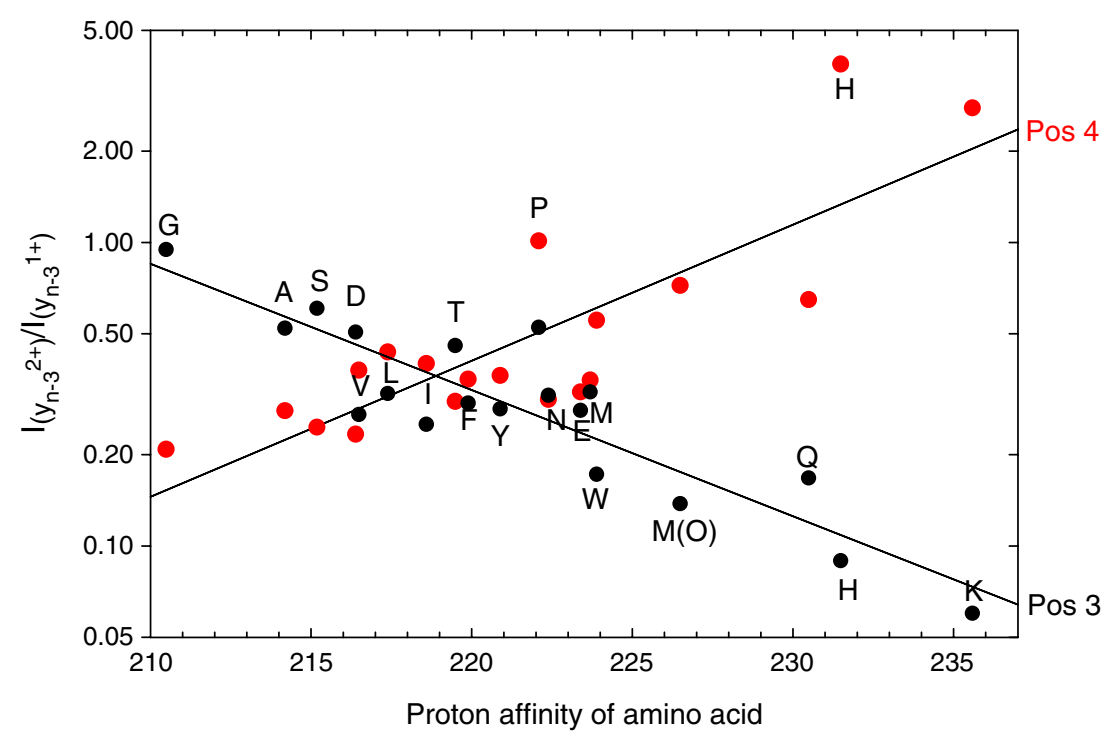

Figure 4. The average values of $\mathrm{I}\left(\mathrm{y}_{\mathrm{n}-3^{2+}}\right) / \mathrm{I}\left(\mathrm{y}_{\mathrm{n}-3^{1+}}\right)$ for peptides with 10 to 13 amino acid residues (from Figure 3) with specific residues at position 3 or 4 vs. the proton affinities of the amino acids at these positions 


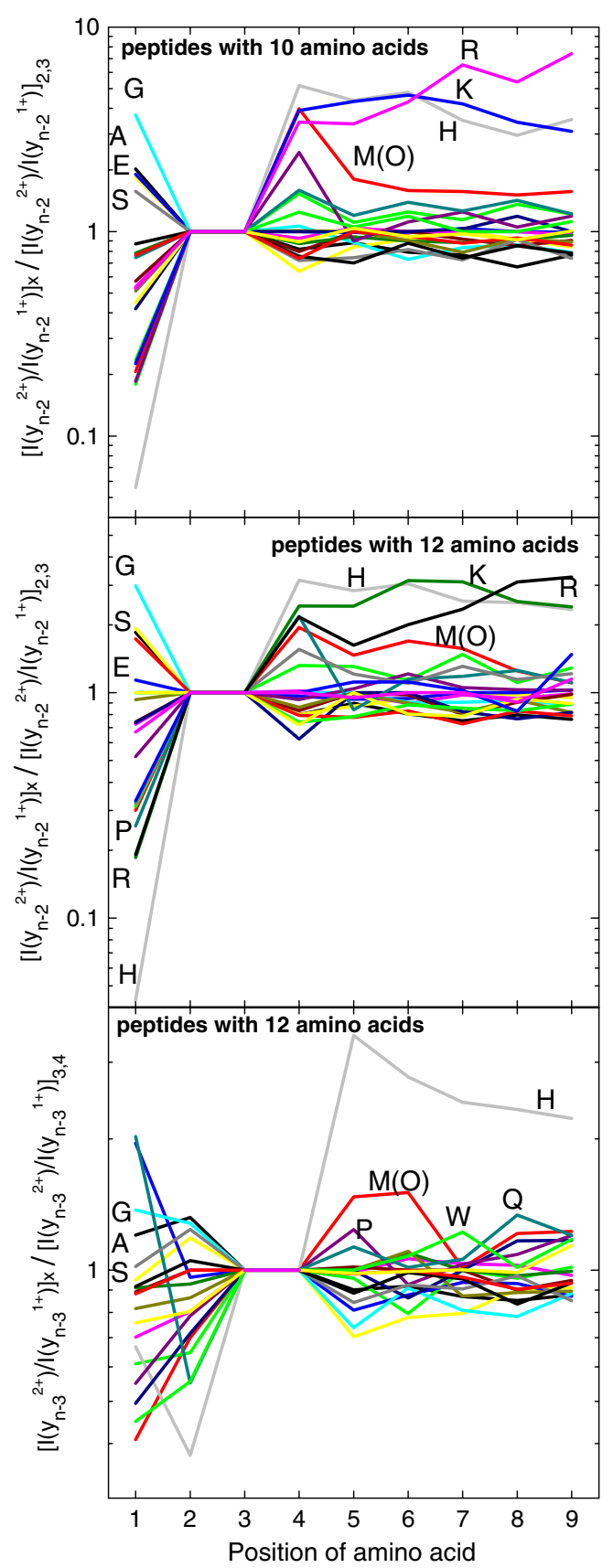

Figure 5. Relative intensities of $\mathrm{y}^{2+} v s$. $\mathrm{y}^{1+}$ for peptide ions with specific amino acids at remote positions, normalized to the values for the residues at the dissociating peptide bond. Top values of $\left[I\left(y_{n-2}{ }^{2+}\right) / I\left(y_{n-2}{ }^{1+}\right)\right] \times /\left[I\left(y_{n-2}{ }^{2+}\right) / I\left(y_{n-2}{ }^{1+}\right)\right]_{2,3}$ for peptides with 10 amino acid residues as a function of the position of the specific residue. Middle - values of $\left[\mathrm{l}\left(\mathrm{y}_{\mathrm{n}-2^{2+}}\right) / \mathrm{I}\left(\mathrm{y}_{\mathrm{n}-2}{ }^{1+}\right)\right]_{\mathrm{x}} /\left[\mathrm{l}\left(\mathrm{y}_{\mathrm{n}-2^{2+}}\right) / \mathrm{I}\right.$ $\left.\left(\mathrm{y}_{\mathrm{n}-2}{ }^{1+}\right)\right]_{2,3}$ for peptides with 12 amino acid residues as a function of the position of the specific residue. Bottom - values of $\left[1\left(y_{n-3}{ }^{2+}\right) /\right.$ $\left.\mathrm{I}\left(\mathrm{y}_{\mathrm{n}-3^{1+}}\right)\right]_{\times} /\left[\mathrm{I}\left(\mathrm{y}_{\mathrm{n}-3^{2+}}\right) / \mathrm{I}\left(\mathrm{y}_{\mathrm{n}-3^{1+}}\right)\right]_{3,4}$ for peptides with 12 amino acid residues as a function of the position of the specific residue

fragments from multiply charged peptide ions was examined in the spectra of 8400 peptide ions [4] and was correlated with the presence of basic residues in the middle of the peptide $[2,4]$, with the extent of proton mobility along the peptide chain, and with specific amino acid bonding sites, such as proline and aspartic acid [4]. In this study we expand these observations by examining over 250,000 CID spectra of doubly charged tryptic peptide ions contained within six libraries in our collection, where we can fully separate effects due to peptide length from effects due to amino acid location. We find that the relative intensities of $y^{2+}$ over $y^{1+}$ ions vary over three orders of magnitude and depend on peptide length, on $\mathrm{C}$-terminal $\mathrm{K} v s$. $\mathrm{R}$, on the proton affinities of the amino acid residues at the dissociating bond, and on the presence of basic residues along the chain. Additional effects were found for specific residues at specific positions.

The most prevalent dissociation of doubly charged tryptic peptide ions is between position 2 and 3 . The ratio of intensities $\mathrm{I}\left(\mathrm{y}_{\mathrm{n}-2}{ }^{2+}\right) / \mathrm{I}\left(\mathrm{y}_{\mathrm{n}-2}{ }^{1+}\right)$ depends very strongly on the residues at these positions; it increases with increasing proton affinity of the residue at position 3 and decreases with increasing proton affinity of the residue at position 2 (Figure 2). In other words, if the amino acid remains with the $y$ ion, its increasing proton affinity increases the likelihood of producing a doubly charged y ion. Strongly basic residues such as histidine exert such an effect even when they are remote from the dissociating bond, but for most amino acids the effect diminishes greatly with distance.

Essentially the same effects are expected for peptide dissociation at other positions. This is demonstrated in this study for cleavage between positions 1 and 2 and between positions 3 and 4 . In all cases there is a clear correlation between the ratio of intensities of $\mathrm{y}^{2+} / \mathrm{y}^{1+}$ and the proton affinity of the amino acids at the cleaving bond. The quantitative correlation, however, is somewhat different for the various bonds (Supplementary Figure S6). The correlation between $y_{n-3}$ and $y_{n-2}$ (lower line, red symbols) is quite good although the slope is lower (as compared with $\mathrm{y}_{\mathrm{n}-2} v s . \mathrm{y}_{\mathrm{n}-2}$, dashed line). The correlation between $\mathrm{y}_{\mathrm{n}-1}$ and $\mathrm{y}_{\mathrm{n}-2}$ (upper line, green symbols) has the same slope (as $\mathrm{y}_{\mathrm{n}-2}$ vs. $\mathrm{y}_{\mathrm{n}-2}$ ) but the values are shifted upward. The high sensitivity of bonds 1-2 and 2-3 compared to others is apparently connected to the quite difference transition states discussed for their fragmentation [3].

For the important case of $y_{n-2}$ ions the relative intensities of doubly charged to singly charged ions can be predicted from the proton affinity of the amino acid at position 2 or 3 . The correlation has significant scatter (Figure 2), probably because the proton affinities of the residues within the peptide ion are different from the proton affinities of the amino acid molecules used in the correlation. For this reason, the actual values of $\mathrm{I}\left(\mathrm{y}_{\mathrm{n}-2}{ }^{2+}\right) / \mathrm{I}\left(\mathrm{y}_{\mathrm{n}-2}{ }^{1+}\right)$ found in this study are likely to be better predictors of such values for other peptides than the proton affinities. One may speculate that the $\mathrm{I}\left(\mathrm{y}_{\mathrm{n}-2}{ }^{2+}\right) / \mathrm{I}\left(\mathrm{y}_{\mathrm{n}-2}{ }^{1+}\right)$ values derived in this study are better measures of proton affinities of amino acid residues than the actual proton affinities of the amino acid molecules. At the least, these values are good measures of the relative stabilities of protonation sites of peptides. 
Table 1. Ratio of intensities of $\mathrm{y}$ ions $\left(\mathrm{y}^{2+} / \mathrm{y}^{1+}\right)$ for $\mathrm{y}_{\mathrm{n}-1}, \mathrm{y}_{\mathrm{n}-2}$, and $\mathrm{y}_{\mathrm{n}-3}$ in the CID spectra of doubly charged peptide ions C-terminated with $\mathrm{R} v$. $\mathrm{K}$

\begin{tabular}{|c|c|c|c|c|c|c|}
\hline \multirow[t]{2}{*}{ length ${ }^{\mathrm{a}}$} & \multicolumn{3}{|c|}{$\mathrm{R}$} & \multicolumn{3}{|c|}{$\mathrm{K}$} \\
\hline & $\mathrm{y}^{2+} / \mathrm{y}^{1+}$ & $d^{b}$ & $\mathrm{n}^{\mathrm{c}}$ & $\mathrm{y}^{2+} / \mathrm{y}^{1+}$ & $\mathrm{d}^{\mathrm{b}}$ & $n^{\mathrm{c}}$ \\
\hline \multicolumn{7}{|l|}{$\mathrm{y}_{\mathrm{n}-1}$} \\
\hline 6 & 0.253 & 4.06 & 1055 & 0.113 & 4.3 & 820 \\
\hline 7 & 0.676 & 3.5 & 3648 & 0.314 & 4.14 & 2948 \\
\hline 8 & 1.110 & 2.9 & 4808 & 0.666 & 3.97 & 4372 \\
\hline 9 & 1.695 & 2.61 & 4400 & 1.177 & 3.27 & 4886 \\
\hline 10 & 2.391 & 2.29 & 3194 & 1.579 & 2.7 & 4316 \\
\hline 11 & 2.833 & 2.19 & 2061 & 1.953 & 2.41 & 3133 \\
\hline 12 & 3.721 & 2.22 & 871 & 2.541 & 2.25 & 1748 \\
\hline 13 & 3.919 & 2.14 & 354 & 2.821 & 2.22 & 857 \\
\hline 14 & 4.655 & 2.88 & 122 & 2.889 & 2.47 & 348 \\
\hline 15 & 5.253 & 2.3 & 45 & 2.690 & 2.37 & 166 \\
\hline \multicolumn{7}{|l|}{$\mathrm{y}_{\mathrm{n}-2}$} \\
\hline 6 & 0.029 & 3.09 & 1087 & 0.015 & 2.78 & 635 \\
\hline 7 & 0.071 & 3.74 & 4907 & 0.024 & 3.01 & 3010 \\
\hline 8 & 0.166 & 3.83 & 8254 & 0.075 & 3.9 & 6297 \\
\hline 9 & 0.312 & 3.52 & 9687 & 0.165 & 4.04 & 8675 \\
\hline 10 & 0.560 & 3.42 & 9428 & 0.312 & 3.7 & 9733 \\
\hline 11 & 0.944 & 3.31 & 8839 & 0.593 & 3.43 & 9705 \\
\hline 12 & 1.504 & 3.2 & 6997 & 0.988 & 3.28 & 8507 \\
\hline 13 & 2.284 & 3 & 5271 & 1.645 & 3.01 & 6749 \\
\hline 14 & 3.103 & 2.84 & 3722 & 2.255 & 2.89 & 4996 \\
\hline 15 & 3.960 & 2.8 & 2392 & 3.063 & 2.8 & 3608 \\
\hline \multicolumn{7}{|l|}{$\mathrm{y}_{\mathrm{n}-3}$} \\
\hline 6 & 0.052 & 1.96 & 67 & 0.176 & 2.87 & 5 \\
\hline 7 & 0.039 & 2.39 & 1476 & 0.073 & 2.34 & 834 \\
\hline 8 & 0.053 & 2.34 & 3063 & 0.043 & 2.43 & 1528 \\
\hline 9 & 0.080 & 2.41 & 4329 & 0.055 & 2.31 & 2909 \\
\hline 10 & 0.122 & 2.55 & 4678 & 0.083 & 2.45 & 3958 \\
\hline 11 & 0.196 & 2.53 & 5074 & 0.138 & 2.49 & 4768 \\
\hline 12 & 0.336 & 2.43 & 4586 & 0.223 & 2.45 & 4646 \\
\hline 13 & 0.522 & 2.53 & 4099 & 0.353 & 2.42 & 4361 \\
\hline 14 & 0.750 & 2.4 & 3471 & 0.559 & 2.34 & 3760 \\
\hline 15 & 1.113 & 2.38 & 2837 & 0.853 & 2.46 & 3436 \\
\hline
\end{tabular}

alength of peptide, number of amino acid residues.

${ }^{\mathrm{b}}$ median absolute deviation ( $1=$ relative no deviation).

${ }^{c}$ number of spectra.

In addition to the effect of proton affinity, there are site specific effects of certain amino acids. In the formation of $\mathrm{y}_{\mathrm{n}-2}$ ions, proline at position 3 is known to enhance such dissociation and it also increases the ratio $\mathrm{I}\left(\mathrm{y}_{\mathrm{n}-2}{ }^{2+}\right) / \mathrm{I}\left(\mathrm{y}_{\mathrm{n}-2}{ }^{1+}\right)$, i.e. proline in this position behaves as a residue with a much higher proton affinity than reflected in the value measured for the amino acid. Proline at position 2 inhibits formation of $\mathrm{y}_{\mathrm{n}-2}$ ions but its position on the correlation curve is in line with other residues (Figure 2), i.e. it does not appear to have a higher proton affinity at this position. An opposite effect is observed for aspartic and glutamic acids, which also exert somewhat different effects at positions 2 and 3 (Figure 2). These acidic residues do not promote fragmentation in doubly charged tryptic peptides (they do so only in the absence of mobile protons [20]), but their acidic side chain appears to decrease the likelihood that a proton be attached to the fragment ion containing these acids.

The basic amino acids, arginine, lysine, and histidine exert strong effects on the ratio $\mathrm{I}\left(\mathrm{y}_{\mathrm{n}-2^{2+}}\right) / \mathrm{I}\left(\mathrm{y}_{\mathrm{n}-2}{ }^{1+}\right)$. When they are adjacent to the dissociating peptide bond they tend to carry the additional charge with them into the fragment ion in which they are contained. But their effect is much stronger than that of any other residue and is evident even when they are remote from the cleaving bond. This is clearly demonstrated for histidine (Figure S3), where the effect barely diminishes with distance from the cleaving bond, while the effects of proline and aspartic acid decrease sharply with distance (Figure S4). Figure 5 also demonstrates the diminishing effect of various residues with distance while the effects of the basic residues remain strong. For C-terminal arginine, it was noted in Figure 1 that its curves show minimal dependence on peptide length, which is due to the strong effect of arginine along the whole peptide chain.

\section{Conclusions}

CID of doubly protonated peptides produces both singlyand doubly-charged ions whose ratios can vary over three orders of magnitude depending on the specific peptide ion and bond being broken. Factors influencing the relative peak intensities of $\mathrm{y}^{2+}$ over $\mathrm{y}^{1+}$ ions have been examined through the use of a very large dataset. This has enabled the quantitative determination of various factors influencing this ratio. Trends examined were the increase of $\mathrm{I}\left(\mathrm{y}^{2+}\right) / \mathrm{I}\left(\mathrm{y}^{1+}\right)$ 
with peptide length, effects of $\mathrm{C}$-terminal $\mathrm{R}$ versus $\mathrm{C}$ terminal $\mathrm{K}$, position of the breaking bond and effects of specific resides at and remote from the cleavage site. The influence of the specific amino acid at the cleavage site was found to closely parallel their proton affinities and, for basic residues, their presence on the fragment ion.

The correlation of $\mathrm{I}\left(\mathrm{y}^{2+}\right) / \mathrm{I}\left(\mathrm{y}^{1+}\right)$ with proton affinity of adjacent amino acids (Figure 2) has significant scatter, probably because the proton affinities of the residues within the peptide ion are different from the proton affinities of the amino acid molecules used in the correlation. Therefore, the actual values of $\mathrm{I}\left(\mathrm{y}_{\mathrm{n}-\mathrm{x}}{ }^{2+}\right) / \mathrm{I}\left(\mathrm{y}_{\mathrm{n}-\mathrm{x}}{ }^{1+}\right)$ found in this study are likely to be better predictors of such values for other peptides than the proton affinities. One may speculate that the $\mathrm{I}\left(\mathrm{y}_{\mathrm{n}-2}{ }^{2+}\right) / \mathrm{I}\left(\mathrm{y}_{\mathrm{n}-2}{ }^{1+}\right)$ values derived in this study are better measures of proton affinities of amino acid residues than the actual proton affinities of the amino acid molecules.

In addition to the effect of proton affinity, there are site specific effects of certain amino acid, such as proline and the acidic residues aspartic and glutamic acids. Whereas these effects are most pronounced when the residue is located at the cleaving peptide bond, the basic amino acids, arginine, lysine, and histidine exert strong effects on the ratio $\mathrm{I}\left(\mathrm{y}_{\mathrm{n}-\mathrm{x}}{ }^{2+}\right) / \mathrm{I}\left(\mathrm{y}_{\mathrm{n}-\mathrm{x}}{ }^{1+}\right)$ even when they are remote from the cleaving bond.

Finally, the specific dependences of $\mathrm{I}\left(\mathrm{y}^{2+}\right) / \mathrm{I}\left(\mathrm{y}^{1+}\right)$ reported here can find use for spectral prediction [21], scoring [22$25]$ and quality control in spectral libraries [13].

\section{References}

1. Aebersold, R., Goodlett, D.R.: Mass spectrometry in proteomics. Chem. Rev. 101, 269-295 (2001)

2. Salek, M., Lehmann, W.D.: Neutral loss of amino acid residues from protonated peptides in collision-induced dissociation generates $\mathrm{N}$ - or Cterminal sequence ladders. J. Mass Spectrom. 38, 1143-1149 (2003)

3. Paizs, B., Suhai, S.: Fragmentation pathways of protonated peptides. Mass Spectrom. Rev. 24, 508-548 (2005)

4. Martin, D.B., Eng, J.K., Nesvizhskii, A.I., Gemmill, A., Aebersold, R.: Investigation of neutral loss during collision-induced dissociation of peptide ions. Anal. Chem. 77, 4870-4882 (2005)

5. Knapp-Mohammady, M., Young, A.B., Paizs, B., Harrison, A.G.: Fragmentation of doubly-protonated Pro-His-Xaa tripeptides: Formation of $\mathrm{b}_{2}{ }^{2+}$ ions. J. Am. Soc. Mass Spectrom. 20, 2135-2143 (2009)

6. Breci, L.A., Tabb, D.L., Yates, J.R.I.I.I., Wysocki, V.H.: Cleavage Nterminal to proline: analysis of a database of peptide tandem mass spectra. Anal. Chem. 75, 1963-1971 (2003)

7. Kapp, E.A., Schutz, F., Reid, G.E., Eddes, J.S., Moritz, R.L., O’Hair, R. A.J., Speed, T.P., Simpson, R.J.: Mining a tandem mass spectrometry database to determine the trends and global factors influencing peptide fragmentation. Anal. Chem. 75, 6251-6264 (2003)
8. Huang, Y., Triscari, J.M., Pasa-Tolic, L., Anderson, G.A., Lipton, M.S., Smith, R.D., Wysocki, V.H.: Dissociation behavior of doubly-charged tryptic peptides: Correlation of gas-phase cleavage abundance with Ramachandran plots. J. Am. Chem. Soc. 126, 3034-3035 (2004)

9. Huang, Y., Triscari, J.M., Tseng, G.C., Pasa-Tolic, L., Lipton, M.S., Smith, R.D., Wysocki, V.H.: Statistical characterization of the charge state and residue dependence of low-energy CID peptide dissociation patterns. Anal. Chem. 77, 5800-5813 (2005)

10. Barton, S.J., Richardson, S., Perkins, D.N., Bellahn, I., Bryant, T.N., Whittaker, J.C.: Using statistical models to identify factors that have a role in defining the abundance of ions produced by tandem MS. Anal. Chem. 79, 5601-5607 (2007)

11. Savitski, M.M., Fälth, M., Fung, Y.M.E., Adams, C.M., Zubarev, R.A.: Bifurcating fragmentation behavior of gas-phase tryptic peptide dications in collisional activation. J. Am. Soc. Mass Spectrom. 19, 17551763 (2008)

12. Barton, S.J., Whittaker, J.C.: Review of factors that influence the abundance of ions produced in a tandem mass spectrometer and statistical methods for discovering these factors. Mass Spectrom. Rev. 28, 177-187 (2009)

13. Lam, H., Deutsch, E.W., Eddes, J.S., Eng, J.K., Stein, S.E., Aebersold, R.: Building consensus spectral libraries for peptide identification in proteomics. Nat. Meth. 5, 873-875 (2008)

14. Loevenich, S.N., Brunner, E., King, N.L., Deutsch, E.W., Stein, S.E., Aebersold, R., Hafen, E.: The drosophila melanogaster PeptideAtlas facilitates the use of peptide data for improved fly proteomics and genome annotation. BMC BIOINFORMATICS, 10, Article 59 (on line) (2009)

15. Godugu, B., Neta, P., Simon-Manso, Y., Stein, S.E.: Effect of Nterminal glutamic acid and glutamine on fragmentation of peptide ions. J. Am. Soc. Mass Spectrom. 21, 1169-1176 (2010)

16. Bleiholder, C., Suhai, S., Paizs, B.: Revising the proton affinity scale of the naturally occurring $\alpha$-amino acids. J. Am. Soc. Mass Spectrom. 17, 1275-1281 (2006)

17. Harrison, A.G.: The gas-phase basicities and proton affinities of amino acids and peptides. Mass Spectrom. Rev. 16, 201-217 (1997)

18. Hunter, E.P., Lias, S.G.: Evaluated gas-phase basicities and proton affinities of molecules: an update. J. Phys. Chem. Ref. Data 27, 413656 (1998)

19. Lioe, H., O’Hair, R.A.J., Gronert, S., Austin, A., Reid, G.E.: Experimental and theoretical proton affinities of methionine, methionine sulfoxide and their $\mathrm{N}$ - and C-terminal derivatives. Int. J. Mass Spectrom. 267, 220-232 (2007)

20. Gu, C., Tsaprailis, G., Breci, L., Wysocki, V.H.: Selective gas-phase cleavage at the peptide bond $\mathrm{C}$-terminal to aspartic acid in fixedcharged derivatives of Asp-containing peptides. Anal. Chem. 72, 58045813 (2000)

21. Zhang, Z.Q.: Prediction of low-energy collision-induced dissociation spectra of peptides. Anal. Chem. 76, 3908-3922 (2004)

22. Havilio, M., Haddad, Y., Smilansky, Z.: Intensity-based statistical scorer for tandem mass spectrometry. Anal. Chem. 75(3), 435-444 (2003)

23. Elias, J.E., Gibbons, F.D., King, O.D., Roth, F.P., Gygi, S.P.: Intensitybased protein identification by machine learning from a library of tandem mass spectra. Nat. Biotechnol. 22, 214-219 (2004)

24. Sadygov, R., Wohlschlegel, J., Park, S.K., Xu, T., Yates, J.R.: III. Central Limit Theorem as an Approximation for Intensity-Based Scoring Function. Anal. Chem. 78, 89-95 (2006)

25. Sun, S., Meyer-Arendt, K., Eichelberger, B., Brown, R., Yen, C.-Y., Old, W.M., Pierce, K., Cios, K.J., Ahn, N.G., Resing, K.A.: Improved validation of Peptide MS/MS assignments using spectral intensity prediction. Mol. Cell. Proteomics 6, 1-17 (2007) 